Article

\title{
Distribution and Genotyping of Aquatic Acinetobacter baumannii Strains Isolated from the Puzi River and Its Tributaries Near Areas of Livestock Farming
}

\author{
Hsin-Chi Tsai ${ }^{1,2}{ }^{\text {, Ming-Yuan Chou }}{ }^{3,+}$, Yi-Jia Shih ${ }^{4,5,6, \dagger}$, Tung-Yi Huang ${ }^{4,+}$, Pei-Yu Yang ${ }^{7, \dagger}$, \\ Yi-Chou Chiu ${ }^{8}$, Jung-Sheng Chen ${ }^{4}$ and Bing-Mu Hsu ${ }^{4,9, * \mathbb{D}}$ \\ 1 Department of Psychiatry, School of Medicine, Tzu Chi University, Hualien 970, Taiwan; \\ css30bmw@yahoo.com.tw \\ 2 Department of Psychiatry, Buddhist Tzu-Chi General Hospital, Hualien 970, Taiwan \\ 3 Department of Internal Medicine, Cheng Hsin Hospital, Taipei 111, Taiwan; colin73915@hotmail.com \\ 4 Department of Earth and Environmental Sciences, National Chung Cheng University, Chiayi 621, Taiwan; \\ eja0313@gmail.com (Y.-J.S.); tyhuang27@gmail.com (T.-Y.H.); nicky071214@gmail.com (J.-S.C.) \\ 5 Department of Biotechnology, Xiamen Ocean Vocational College, Xiamen 361000, China \\ 6 Fisheries College, Jimei University, Xiamen 361000, China \\ 7 Department of Laboratory, Show Chwan Memorial Hospital, Changhua 500, Taiwan; \\ peyyuh2900@gmail.com \\ 8 General Surgery, Surgical Department, Cheng Hsin General Hospital, Taipei 111, Taiwan; \\ ejchiu3@yahoo.com.tw \\ 9 Center for Innovative on Aging Society (CIRAS), National Chung Cheng University, Chiayi 621, Taiwan \\ * Correspondence: bmhsu@ccu.edu.tw; Tel.: +886-952840868; Fax: +886-5-2720807 \\ + Ming-Yuan Chou, Yi-Jia Shih, Tung-Yi Huang and Pei-Yu Yang have equal contributions to the first author.
}

Received: 1 July 2018; Accepted: 28 September 2018; Published: 1 October 2018

\begin{abstract}
Acinetobacter baumannii is an important health care-associated bacterium and a common multidrug-resistant pathogen. The use of antibiotics in the husbandry industry has raised concerns about drug-resistant $A$. baumannii strains, which may affect humans. This study aimed to investigate the seasonal distribution of $A$. baumannii in aquatic environments near areas of livestock farming. The geographic distribution, antibiotic resistance characteristic, and DNA fingerprinting genotype of $A$. baumannii were also studied. The results showed that environmental $A$. baumannii was prevalent during the summer and autumn. The hotspots for A. baumannii were found at the sampling sites of livestock wastewater channels $(21.4 \% ; 3 / 14)$ and the tributaries adjacent to livestock farms $(15.4 \%$; $2 / 13)$. The prevalence of $A$. baumannii at these locations was significantly higher than those adjacent to the Puzi River. Multidrug-resistant strain of A. baumannii was not found in this study, with only one strain $(5 \% ; 1 / 20)$ being resistant to tetracycline. Of the isolates that were obtained, $10 \%(2 / 20)$ and $20 \%$ $(4 / 20)$ were found to be intermediately resistant to tetracycline and sulphamethoxazole/trimethoprim, respectively. The genotyping patterns and clustering analysis indicated that enterobacterial repetitive intergenic consensus sequence polymerase chain reaction (ERIC-PCR) differentiated A. baumannii strains effectively. There were two major clusters that could then be subtyped into $20 \mathrm{~A}$. baumannii strains with 15 profiles. The A. baumannii strains that were isolated from upstream of the Puzi River and livestock wastewater channels were composed of Cluster I. Cluster II only contained isolates from downstream of the Puzi River area. Furthermore, isolates from adjacent sites were shown to have identical profiles $(100 \%)$. These results suggest that $A$. baumannii may have spread through free-flowing water in this study. Therefore, we propose that livestock wastewater is one of the sources that contribute to A. baumannii pollution in water bodies. In summary, continuous monitoring of antibiotic pollution in livestock wastewater is required.
\end{abstract}


Keywords: Acinetobacter baumannii; antibiotic-resistant strains; aquatic environment; ERIC-PCR

\section{Introduction}

Acinetobacter baumannii is a Gram-negative, non-fermenting, aerobic bacterium [1-3] which is considered to be ubiquitous as it can be recovered from various environments, including soil or surface water [4-7]. It is also an important health care-associated pathogen, which mostly causes opportunistic infections in immunocompromised individuals [6]. The most prevalent symptoms that are caused by $A$. baumannii in hospitals include urinary tract infection, meningitis, bacteraemia, peritonitis, surgical wound infection, and pneumonia $[4,8,9]$. Many studies have surveyed the mortality rate of the pathogen, which ranged from $5 \%$ in general wards to more than $60 \%$ in patients suffering from multidrug-resistant $A$. baumannii infections $[8,10]$. In the treatment of various $A$. baumannii infections, a reliable method for identification and characterization of the strains is necessary. Numerous methods have been developed for analysis and molecular typing of A. baumannii, such as plasmid analysis, ribotyping, multilocus sequence genotyping (MLST), pulsed-field gel electrophoresis (PFGE), and several other sequence-based polymerase chain reaction (PCR) typing techniques [2,4,6,11-13]. Despite MLST and PFGE being highly discriminative genotyping methods, sequence-based DNA fingerprinting PCR techniques have advantages of performance ease and economic viability $[2,12,14]$. Since the enterobacterial repetitive intergenic consensus polymerase chain reaction (ERIC-PCR) technique has a sound discrimination index (over 94\%) [12] and a relatively low cost for large-scale genotyping of $A$. baumannii when compared with other sequence-based PCR techniques, it has been widely adopted in the studies of environmental $A$. baumannii studies.

Multidrug-resistant $A$. baumannii (MDR-AB) is referred to as resistance to three out of four antibiotic classes, namely ceftazidime, ciprofloxacin, gentamicin, and imipenem [15]. As the scale of antibiotic adoption in clinical treatment increases, the presence of MDR-AB also increases, which poses a great challenge for public health; therefore, surveillance of environmental A. baumannii is urgent $[8,16]$. Recently, it has been reported that the incidence of nosocomial MDR-AB infection has elevated significantly. As such, the presence of MDR-AB in the environment could increase the risk of infection [8,17-19].

A. baumannii exists not only in hospitals, but also in its natural habitats, such as soil, surface water, human skin, and inorganic surfaces [6,20-23]. Antimicrobial agents are widely used in livestock and aquaculture to suppress the growth of bacteria and to boost survival rates [24-26]. However, residue antibiotic agents from various sources, such as waste animal feed and animal excrement, can leak into the environment as active ingredients. Indeed, environmental studies have proven that there were substantial amounts of various antibiotic compounds in soils [27]. Long-term antibiotic contamination can change the gene profile of bacteria in livestock and natural habitats. For example, sulfonamide-resistance genes (sul1, sul2, and sul3) have commonly been found in aquatic environments in northern Vietnam, and they have been isolated from the excrement of pigs suffering from diarrhea in Ontario [28,29]. These reports provide evidence that the use of antibiotics in the husbandry industry may promote the emergence of antibiotic-resistant bacteria. The most commonly used livestock-associated antibiotic classes include aminoglycosides, cephalosporins, chloramphenicol, lincosamides, macrolides, penicillins, polyether ionophores, polypeptides, and tetracyclines, with tetracyclines and macrolides combined products as the most frequently used antibiotic agents [24,30-32]. The increased use of antibiotics in livestock and aquaculture could lead to an increase in the population of antibiotic-resistant $A$. baumannii strains, causing the environment to act as a reservoir of these populations [26].

In recent years, many studies have focused on the epidemiology and analysis of antibiotic resistance, resistance mechanisms, and novel treatments of $A$. baumannii $[4,6,19,33]$. However, evaluations on the impact of antibiotic usage on the environment were less clear. Many studies have 
revealed that antibiotic residues can be observed in liquid manure from pig husbandries, suggesting that microorganisms surrounding the aquatic environment near these husbandries are affected by these antibiotic residues and result in the risk of natural selection of these antibiotic-resistant pathogens from the environment. The aim of this study was to understand the seasonal variability and antibiotic susceptibility profiles of $A$. baumannii in the Puzi River and its tributaries near areas of livestock farming and to characterise A. baumannii in aquatic environments using the ERIC-PCR method.

\section{Materials and Methods}

\subsection{Collection and Concentration of Water Samples}

Monthly water samples were collected from the Puzi River from May 2014 to April 2015. Water samples were collected from 32 locations. Subsequently, these 32 locations were separated into three areas based on our previous studies [34] (Figure 1); sites PR01-PR12 (Area A) are located upstream of the Puzi River, sites PR14-PR25 (Area B) are located midstream, and sites PR26-PR34 (Area C) are located downstream. Additionally, water samples from the livestock wastewater channel, household wastewater channel, and tributary were collected at 30 locations around the Puzi River in October 2015. The sampling sites are summarised in Figure 2. At each sampling site, a water sample of approximately $3000 \mathrm{~mL}$ was collected for pathogen detection. Each water sample was stored in three sterile one-litre bottles and was transported to the laboratory at $4{ }^{\circ} \mathrm{C}$ within $24 \mathrm{~h}$ for analysis.

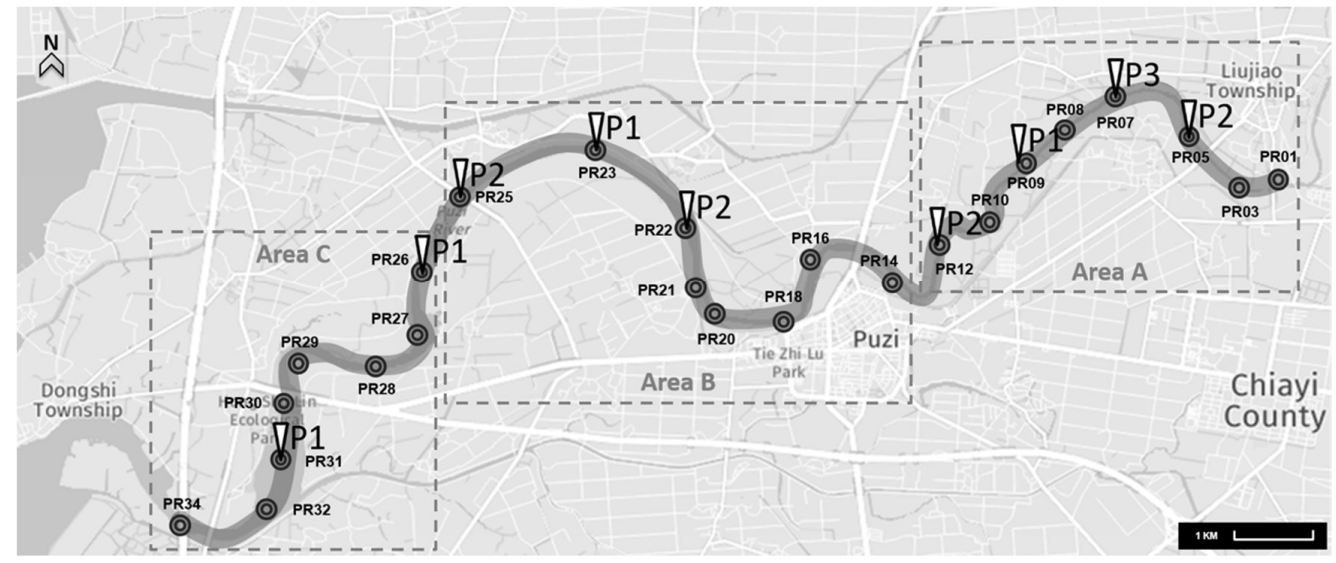

Figure 1. Sampling locations on the Puzi River in this study ( $\mathrm{P}$ indicates the distribution of Acinetobacter baumannii; numbers indicate the number of strains detected).

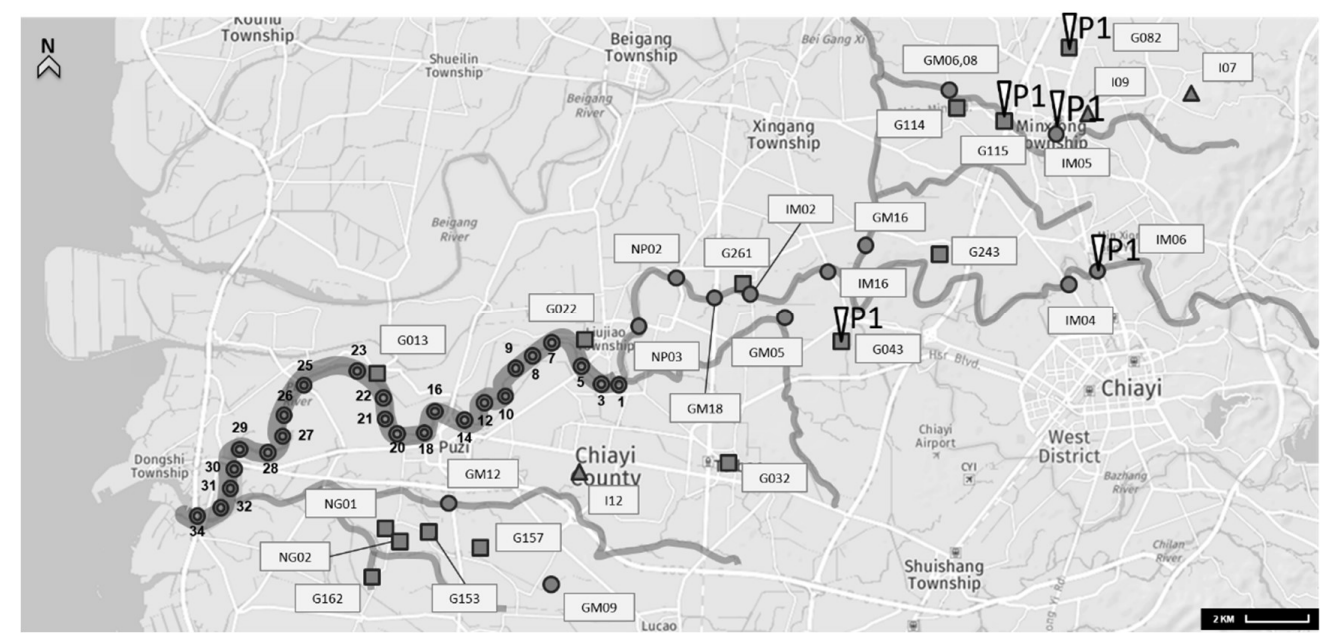

Figure 2. Sampling locations of wastewater surrounding the Puzi River basin in this study (P indicates the distribution of Acinetobacter baumannii; numbers indicate the number of isolates detected). 
For the detection of specific microbial pathogens, $300 \mathrm{~mL}$ of each water sample was filtered through $47 \mathrm{~mm}$ GN-6 membranes (Pall, Mexico City, Mexico) with a pore size of $0.45 \mu \mathrm{m}$, in a stainless steel filter holder. Subsequently, the membranes were used for sample enrichment of each specific pathogen.

\subsection{Enrichment and Identification of $A$. baumannii}

For A. baumannii enrichment, the samples that remained on the membranes after filtration were cultured in MacConkey Broth (HIMEDIA, M007, Taipei, Taiwan). Each sample was selectively cultured on CHROMagar ${ }^{\mathrm{TM}}$ Acinetobacter (CHROMagar, Paris, France) and 5\% sheep blood agar (TPM, TPM150M, Taiwan). Subsequently, the agar plates were incubated at $30{ }^{\circ} \mathrm{C}$ for $24 \mathrm{~h}$.

DNA extraction was performed using $1 \mathrm{~mL}$ of the concentrated pellet from MacConkey Broth (including each suspected isolate from CHROMagar ${ }^{\mathrm{TM}}$ Acinetobacter agar that underwent re-amplification), using a MagPurix 12s Automated Nucleic Acid Purification System (Zinexts Life Science Corp., New Taipei City, Taiwan) for automated DNA extraction and a MagPurix Viral DNA Extraction Kit ZP02006, according to the manufacturer's manual. Total DNA eluate of A. baumannii $(2 \mu \mathrm{L})$ was mixed with primers $(1 \mu \mathrm{L}, 0.4 \mu \mathrm{M}), 5 \mu \mathrm{L}$ of Fast-Run Taq Master Mix with Dye, and $16 \mu \mathrm{L}$ of deionised water to yield a final reaction volume of $25 \mu \mathrm{L}$. The primers that were used in this study were P-Ab-ITSF: 5'-CAT TAT CAC GGT AAT TAG TG-3' and P-AbI-TSB: 5'-AGA GCA CTG TGC ACT TAA G-3' [35]. The amplification reaction was performed as follows: denaturation for 5 min at $94{ }^{\circ} \mathrm{C}$, followed by 30 cycles of $30 \mathrm{~s}$ at $95^{\circ} \mathrm{C}, 30 \mathrm{~s}$ at $52{ }^{\circ} \mathrm{C}$, and $30 \mathrm{~s}$ at $72{ }^{\circ} \mathrm{C}$, and a final extension step at $72{ }^{\circ} \mathrm{C}$ for $7 \mathrm{~min}$. For A. baumannii detection, positive control DNA (A. baumannii, ATCC 19606) was also included in each run. The PCR products were electrophoresed on a $2 \%$ agarose gel (Biobasic Inc., Markham, ON, Canada), were stained with an ethidium bromide solution, and were visualised under UV light.

\subsection{ERIC-PCR for A. baumannii}

ERIC-PCR was performed as described by Soni et al. with modifications [36]. The primers ERIC-1 (5'-ATG TAA GCT CCT GGG GAT TCA C-3') and ERIC-2 (5'-AAG TAA GTG ACT GGG GTG AGC G-3') were synthesised to amplify the ERIC-PCR fingerprints of A. baumannii. The PCR mixture $(25 \mu \mathrm{L})$ was comprising of $200 \mu \mathrm{M}$ of each deoxy-ribonucleotide triphosphate (dNTP), $1.8 \mathrm{U}$ of Taq polymerase (Biolabs, Ipswich, MA, USA), $3 \mathrm{mM}$ of $\mathrm{MgCl}_{2}, 10 \mathrm{mM}$ of Tris- $\mathrm{HCl}(\mathrm{pH}=9.0), 1.0 \mu \mathrm{M}$ of each primer, and $50 \mathrm{ng}$ of the DNA templates. An additional amount of sterile distilled water was added to attain a volume of $50 \mu \mathrm{L}$. The amplification reaction was performed as follows: denaturation for $7 \mathrm{~min}$ at $95^{\circ} \mathrm{C}$, followed by 30 cycles of $1 \mathrm{~min}$ at $95^{\circ} \mathrm{C}, 1 \mathrm{~min}$ at $52{ }^{\circ} \mathrm{C}$, and $8 \mathrm{~min}$ at $65^{\circ} \mathrm{C}$, and a final extension step at $65{ }^{\circ} \mathrm{C}$ for $10 \mathrm{~min}$. The ERIC-PCR products were electrophoresed on a $1.5 \%$ agarose gel (Biobasic Inc., Markham, Canada) containing Tris-acetate-EDTA (TAE) and $1 \mu \mathrm{g} / \mathrm{mL}$ ethidium bromide at $100 \mathrm{~V}$ for $30 \mathrm{~min}$. Subsequently, they were visualised with a UV transilluminator to obtain photographs.

Additionally, the ERIC-PCR patterns were analysed with the Bionumerics software package (Applied Maths, Austin, TX, USA). The relationship between two given isolates was scored using the Jaccard similarity coefficient, and isolates were clustered based on their inter-isolation similarities using the unweighted pair group method with arithmetic averages.

\subsection{Antibiotic Susceptibility of A. baumannii}

All A. baumannii isolates were tested for antibiotic susceptibility by performing the Kirby-Bauer disk diffusion test on Mueller-Hinton agar plates (Becton, Dickinson and Company, Franklin Lakes, NJ, USA) according to the Clinical \& Laboratory Standards Institute (CLSI) [37]. The antibiotics and their dosages that were used for testing in this study included: ciprofloxacin $(5 \mu \mathrm{g})$, cefepime $(30 \mu \mathrm{g})$, gentamicin $(10 \mu \mathrm{g})$, imipenem $(10 \mu \mathrm{g})$, ampicillin/sulbactam $(20 / 10 \mu \mathrm{g})$, sulphamethoxazole/trimethoprim (SXT) $(23.75 / 1.75 \mu \mathrm{g})$, and tetracycline $(30 \mu \mathrm{g})$. 


\section{Results and Discussion}

\subsection{Presence of A. baumannii in the Aquatic Environment}

The observed presence of $A$. baumannii is summarised in Table 1 . The results showed that its detection rate was 3.8\% annually, and that it was most prevalent in May, July, August, and September 2015. The detection rate was highest in May (20.8\%), followed by July (12.5\%). The results indicated that this pathogen occurred more frequently during the summer in aquatic environments. This observation is in accordance with the results of previous studies, which have suggested that A. baumannii is strictly aerobic and thermotropic $\left(37-42^{\circ} \mathrm{C}\right)[6,21,38]$. Furthermore, another study suggested that, during the past decade, the prevalence of this pathogen in hospitals was higher between July and October than between January and June [39]. Moreover, Chu et al. found that in Hong Kong, 53\% of medical students and new nurses were colonised with Acinetobacter during the summer, compared to $32 \%$ in winter [40]. The present study is the first to report the annual distribution of $A$. baumannii and its seasonal fluctuations in natural environments.

The Puzi River was separated into three areas (Figure 1). The highest detection rate of A. baumannii was found in Area A (5.2\%), followed by Area B (4.2\%), while the detection rate in Area C was significantly lower (Table 2). The upstream region of the Puzi River (Area A) displayed the highest annual prevalence. Therefore, wastewaters from different sources, including livestock wastewater channels and tributaries of the Puzi River near livestock farming areas, were sampled to investigate the prevalence of $A$. baumannii in October 2014. The results are shown in Table 2. The detection rate of the pathogen was $21.4 \%(3 / 14)$ in livestock wastewater channels and $15.4 \%(2 / 13)$ in the tributaries of the Puzi River. However, the pathogen was not detected in household wastewater. Figure 2 shows the location of livestock farmlands near the Puzi River. The main location of livestock farming was distributed upstream of the Puzi River $(57 \% ; 8 / 14)$, and the wastewater outlet also flowed into the Puzi River tributaries. These results suggested that $A$. baumannii was transmitted from livestock wastewater into the natural aquatic environment, since the detection rate of this pathogen was higher in wastewater than in the main river. The highest prevalence of $A$. baumannii was in the area upstream of the Puzi River basin. Furthermore, 36\% (5/14) of livestock farmland was distributed in the area downstream of the Puzi River basin, which is close to the estuarine environment, where conditions might not be optimal for A. baumannii growth.

Table 1. Detection rate of Acinetobacter baumannii from the Puzi River per annum.

\begin{tabular}{cccc}
\hline Sampling Date & Positive Samples & Total Samples & Detection Rate \\
\hline 14 May & 5 & 24 & $20.8 \%$ \\
14 June & 0 & 24 & 0 \\
14 July & 3 & 24 & $12.5 \%$ \\
14 August & 1 & 24 & $4.2 \%$ \\
14 September & 2 & 24 & $8.3 \%$ \\
14 October & 0 & 24 & 0 \\
14 November & 0 & 24 & 0 \\
14 December & 0 & 24 & 0 \\
15 January & 0 & 24 & 0 \\
15 February & 0 & 24 & 0 \\
15 March & 0 & 24 & 0 \\
15 April & 0 & 24 & 0 \\
\hline Total & 11 & 288 & $3.8 \%$ \\
\hline
\end{tabular}


Table 2. Detection rate of Acinetobacter baumannii for different sampling areas.

\begin{tabular}{ccccc}
\hline Location & Sites & Positive Samples & Total Samples & Detection Rate \\
\hline \multirow{3}{*}{ Puzi River } & Area A (PR01-PR12) & 5 & 96 & $5.2 \%$ \\
& Area B (PR14-PR25) & 4 & 96 & $4.2 \%$ \\
& Area C (PR26-PR34) & 2 & 96 & $2.1 \%$ \\
\hline \multirow{3}{*}{ Channels and tributaries } & Livestock wastewater channels & 3 & 14 & $21.4 \%$ \\
& Household wastewater channels & 0 & 3 & 0 \\
& Puzi River tributaries & 2 & 13 & $15.4 \%$ \\
\hline
\end{tabular}

Fernando et al. investigated and isolated A. baumannii from a river and nearby dairy farms [38]. Additionally, there are reports that $A$. baumannii isolates, which carried the BLAOXA-23 carbapenemase gene, were isolated from the Seine River in downtown Paris [41] and from the Tietê and Pinheiros rivers in Brazil [42]. Nevertheless, the seasonal distribution and sources of this pathogen remain largely unknown. In previous studies, this organism has primarily been investigated in hospitals and the clinical environment. The results of these studies have consistently indicated that A. baumannii is widespread in nosocomial environments $[4,17,43]$. This organism also prefers to grow in humid conditions. Therefore, the clinical environment acts as a reservoir of $A$. baumannii and leads to opportunistic infections in humans $[9,44,45]$. However, different places in the natural environment, such as rivers, soil, storage tanks in dairy farms, and manure, can also serve as reservoirs for this pathogen [38]. This study first summarises the observed seasonal prevalence of $A$. baumannii in the aquatic environment. The results show that the hotspot basin environment for this pathogen is livestock wastewater. We suggest that the wastewater from livestock farming is a reservoir for A. baumannii. Further, this pathogen spreads into the Puzi River tributary and agricultural irrigation canals through the wastewater that is discharged from livestock wastewater channels. However, the prevalence of A. baumannii that was observed in this environmental survey remained lower than that observed in hospital studies. One possible explanation for this result is that the aquatic environment is constantly changing and, consequently, flowing water does not act as a good reservoir for this microorganism.

\subsection{Antimicrobial Susceptibility}

A total of 20 A. baumannii-positive samples were isolated from 318 water samples, which were dispersed in 16 locations out of 32 research sites (Figures 1 and 2). The results of the antibiotic susceptibility tests in A. baumannii-positive samples are summarised in Table 3. The results show that the positive control strain (ATCC-16906) was highly resistant to SXT, intermediately resistant to tetracycline, and sensitive to other antibiotic agents (Table 4). In addition, the A. baumannii -GI-G11511 strain that was isolated from livestock wastewater was resistant to tetracycline. The A. baumannii-GI-IM0611 strain, which was isolated from the Puzi River tributary and agricultural irrigation canals, was also found to be intermediately resistant to tetracycline. Four strains (A. baumannii PR07-0531, 09-0531, 22-0511, and 23-0521) were isolated from the Puzi River, and they were found to be intermediately resistant to SXT. Additionally, one strain, A. baumannii-PR22-0511, was also found to be intermediately resistant to tetracycline. The other 14 environmental strains were found to be susceptible to all antibiotic agents. These results indicate that most of the isolated strains are quite susceptible to tetracycline. Only $5 \%(1 / 20)$ of the analysed strains were resistant to, and $10 \%(2 / 20)$ intermediately resistant to, tetracycline. Only four strains $(20 \% ; 4 / 20)$ showed intermediate resistance to SXT. Additionally, no multidrug-resistant A. baumannii (MDR-AB) was observed in the aquatic environment. The results for antibiotic susceptibility imply that the A. baumannii that is present in the aquatic environment differs from the $A$. baumannii in hospitals, based on the multidrug-resistant outcome. Therefore, we will analyse the homology between the MDR-AB strains from local hospitals and aquatic environments in our future studies. 
Table 3. Antibiotic susceptibility of environmental Acinetobacter baumannii isolates as determined by Kirby-Bauer disk diffusion tests.

\begin{tabular}{ccccc}
\hline $\begin{array}{c}\text { Antibiotics Resistance } \\
\text { Phenotype }\end{array}$ & Number & Resistant & Intermediate & Susceptible \\
\hline Ciprofloxacin & 20 & 0 & 0 & $20(100 \%)$ \\
Cefepime & 20 & 0 & 0 & $20(100 \%)$ \\
Gentamicin & 20 & 0 & 0 & $20(100 \%)$ \\
Imipenem & 20 & 0 & 0 & $20(100 \%)$ \\
Ampicillin-sulbactam & 20 & 0 & 0 & $20(100 \%)$ \\
Sulphamethoxazole/Trimethoprim & 20 & 0 & $4(20 \%)$ & $16(80 \%)$ \\
Tetracycline & 20 & $1(5 \%)$ & $2(10 \%)$ & $17(85 \%)$ \\
\hline
\end{tabular}

Table 4. Antibiotic susceptibility of different Acinetobacter baumannii isolates from the aquatic environment.

\begin{tabular}{|c|c|c|c|c|c|c|c|c|}
\hline \multirow{2}{*}{ No. } & \multirow{2}{*}{ Code of Strains } & \multicolumn{7}{|c|}{ Antibiotics Resistance Phenotype } \\
\hline & & CIP & FEP & G & I & SAM & SXT & $\mathrm{T}$ \\
\hline 1 & ATCC-16906 & $S$ & $S$ & $S$ & $S$ & $S$ & $\mathrm{R}$ & $\mathrm{I}$ \\
\hline 2 & A. baumannii-PR07-0531 & S & S & $\mathrm{S}$ & S & $\mathrm{S}$ & $\mathrm{I}$ & $\mathrm{S}$ \\
\hline 3 & A. baumannii-PR09-0531 & $S$ & S & $S$ & $\mathrm{~S}$ & $S$ & I & $S$ \\
\hline 4 & A. baumannii-PR21-0511 & S & S & S & S & $\mathrm{S}$ & I & I \\
\hline 5 & A. baumannii-PR23-0521 & $\mathrm{S}$ & $S$ & $S$ & $\mathrm{~S}$ & $S$ & I & $S$ \\
\hline 6 & A. baumannii-PR31-0511 & S & S & $S$ & $S$ & $S$ & $\mathrm{~S}$ & $S$ \\
\hline 7 & A. baumannii-PR07-0711 & S & $\mathrm{S}$ & $\mathrm{S}$ & $\mathrm{S}$ & $\mathrm{S}$ & $S$ & $\mathrm{~S}$ \\
\hline 8 & A. baumannii-PR07-0721 & S & S & $S$ & $\mathrm{~S}$ & $S$ & S & $S$ \\
\hline 9 & A. baumannii-PR22-0711 & $S$ & $S$ & $S$ & $S$ & $S$ & $S$ & $S$ \\
\hline 10 & A. baumannii-PR26-0721 & S & $S$ & $S$ & $S$ & $S$ & $S$ & $S$ \\
\hline 11 & A. baumannii-PR25-0811 & $S$ & S & $S$ & $\mathrm{~S}$ & $S$ & $S$ & $\mathrm{~S}$ \\
\hline 12 & A. baumannii-PR25-0821 & S & S & $S$ & $\mathrm{~S}$ & $\mathrm{~S}$ & $S$ & $\mathrm{~S}$ \\
\hline 13 & A. baumannii-PR05-0911 & $S$ & $S$ & $S$ & $S$ & $S$ & $S$ & $S$ \\
\hline 14 & A. baumannii-PR05-0912 & $S$ & $S$ & $S$ & $S$ & $S$ & $S$ & $S$ \\
\hline 15 & A. baumannii-PR12-0911 & $S$ & S & S & S & $\mathrm{S}$ & $S$ & $\mathrm{~S}$ \\
\hline 16 & A. baumannii-PR12-0912 & $S$ & $S$ & $S$ & $S$ & $S$ & $S$ & $S$ \\
\hline 17 & A. baumannii-GI-IM0511 & $S$ & S & $S$ & $S$ & $\mathrm{~S}$ & S & S \\
\hline 18 & A. baumannii-GI-IM0611 & $\mathrm{S}$ & $S$ & $S$ & $S$ & $\mathrm{~S}$ & $S$ & I \\
\hline 19 & A. baumannii-GI-G04311 & $S$ & S & S & S & S & S & $\mathrm{S}$ \\
\hline 20 & A. baumannii-GI-G08211 & $S$ & $S$ & $S$ & $S$ & $S$ & $S$ & $\mathrm{~S}$ \\
\hline 21 & A. baumannii-GI-G11511 & $S$ & S & S & S & $\mathrm{S}$ & $\mathrm{S}$ & $\mathrm{R}$ \\
\hline
\end{tabular}

Notes: CIP: Ciprofloxacin, FEP: Cefepime, GEN: Gentamicin, IPM: Imipenem, SAM: Ampicillin-sulbactam, SXT: Sulphamethoxazole/Trimethoprim, T: Tetracycline, R: Resistant, I: Intermediately resistant, S: Susceptible.

To conclude the results, it can be said that the environmental $A$. baumannii strains in this study showed much lower antibiotic resistance than hospital A. baumannii. The results also indicated that the strains that were present in water samples were quite susceptible to, and/or intermediately resistant to, certain antibiotics, including SXT and tetracycline. Previous studies have demonstrated that tetracyclines and SXT are the common classes of antimicrobials that are used in livestock [24,26]. Our observations indicate potential mechanisms by which the frequent use of agricultural antibiotics may lead to the formation of antibiotic-resistant bacteria strains. Such strains also pose potential risks to humans, through the direct transmission of the resistant bacteria by water sources or the transfer of resistance genes from antibiotic-resistant bacteria in the agricultural environment into human pathogens [42,46]. Therefore, it is necessary to understand the mechanism of transmission of MDR-AB strains into aquatic environments. In future studies, we will not only focus on understanding the association between agricultural antibiotic usage conditions and the environmental prevalence of MDR-AB, but also on the analysis of homology between MDR-AB strains from local hospitals and aquatic environments. 


\subsection{ERIC-PCR Fingerprint Analysis}

A total of 20 A. baumannii strains were further characterised for strain genotyping and were compared with a reference strain (ATCC 16906) using ERIC-PCR analysis. Five isolates were collected from livestock wastewater and the Puzi River tributaries near livestock farming areas, and 15 isolates were collected from the Puzi River basin. The standard that was used to determine the degree of similarity between different ERIC-PCR fingerprints was based on similarities between the reference strains and the samples from the different $A$. baumannii colonies at the same sampling sites (Site No. PR05, 07, 12, and 25). According to the ERIC-PCR analysis, the Jaccard similarity coefficient between the two reference strains was $85 \%$. The isolates from different colonisation areas at the four sampling sites (A. baumannii-PR12-0911 vs. A. baumannii-PR12-0912, A. baumannii-PR05-0911 vs. A. baumannii- PR05-0912, A. baumannii-PR25-0811 vs. A. baumannii-PR25-0821, and A. baumannii -PR07-0711 vs. A. baumannii-PR07-0721) showed a Jaccard similarity coefficient of $100 \%$, which was used to confirm the genotyping (Figure 3). Two major clusters were observed at a similarity level of less than $20 \%$, and 20 A. baumannii strains were subtyped into 15 profiles. The results also showed that the strains from Area A of the Puzi River were similar to the livestock wastewater and belonged to cluster I (bootstrap value ( $p$-value) $=90 \%$ ). Further, cluster II contained isolates from the other Puzi River area ( $p$-value $=90 \%$ ) (Figure 3). Maleki et al. (2016) found that the diversity of genetic patterns of $A$. baumannii that were observed by ERIC-PCR analysis was due to the wide distribution in hospitals [2]. Here, we postulate that this high diversity is due to the distributions of sampling sites with different sources. Strains A. baumannii-PR22-0511 and A. baumannii-PR23-0521 from two adjacent sampling sites showed an identical profile (100\% similarity). This result suggests that one mechanism of A. baumannii transmission is through free-flowing water, which leads to spreading to other aquatic environments.
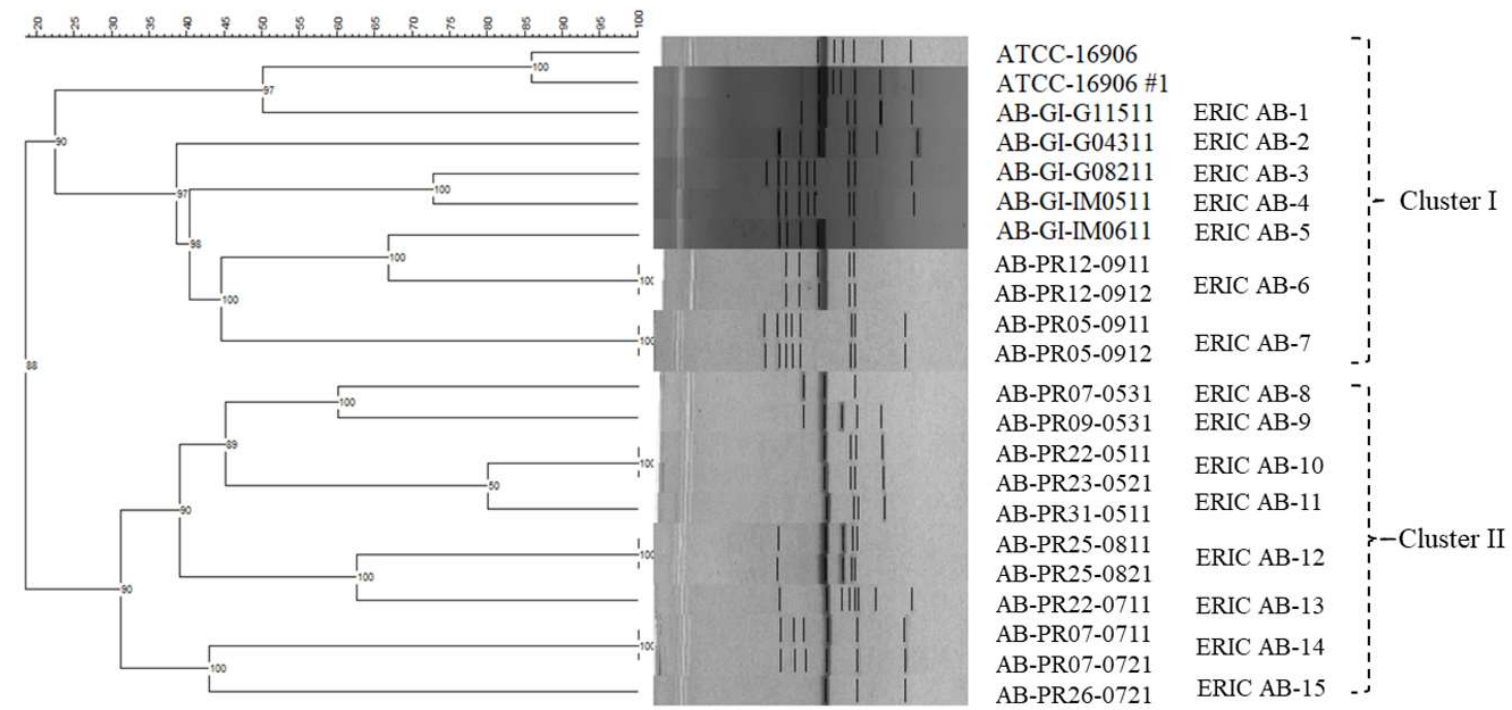

Figure 3. Amplification clustering patterns of Acinetobacter baumannii (AB) by enterobacterial repetitive intergenic consensus PCR (ERIC-PCR).

We regard the genotyping of $A$. baumannii isolates as a necessary means to control the epidemic that has been caused by this organism. Therefore, different DNA fingerprinting techniques have been developed for the quick and accurate classification of $A$. baumannii isolates. Molecular genotyping methods, including plasmid profiling, ribotyping, PFGE, MLST, and PCR-based typing methods, have been evaluated as potential methods to characterise $A$. baumannii isolates [6]. Despite MLST and PFGE being highly discriminative genotyping methods, PCR-based DNA fingerprinting techniques have advantages of performance ease and economic viability $[2,6,12]$. To date, there have been many studies describing different PCR-based methods to type MDR-AB [47-49]. In general, the ERIC-PCR method 
is a common, easy, and quick fingerprinting technique for characterising A. baumannii isolates $[2,48,49]$. The results of this study indicate that the ERIC-PCR method is useful for the analysis of genetic variation among environmental $A$. baumannii isolates.

\section{Conclusions}

In this study, we first investigated the seasonal temporal distribution and antibiotic resistance of A. baumannii in natural aquatic environments. In conclusion, the seasonal prevalence of $A$. baumannii and the percentage of antibiotic-resistant $A$. baumannii isolates in water bodies were found to be lower than those in known nosocomial environments. However, we observed that the highest detection rate of A. baumannii occurred in livestock wastewater. We also observed one tetracycline-resistant strain. In addition, four strains were found to be intermediately resistant to SXT, and one was intermediately resistant to tetracycline. These results indicate the necessity of monitoring on the use of antimicrobials in livestock. Further, livestock wastewater is a potential source of $A$. baumannii contamination. This is an important issue for the transmission pathway of A. baumannii between the environment and hospitals, or even long-term care facilities, and is worth further exploration.

Author Contributions: Conceptualization, B.-M.H and H.-C.T; Methodology, Y.-J.S; Software, M.-Y.C; Validation, P-Y.Y, J.-S.C and Y.-C.C; Formal Analysis, J.-S.C and Y.-J.S; Investigation, J.-S.C.; Resources, M.-Y.C; Data Curation, J.-S.C and Y.-J.S; Writing-Original Draft Preparation, H.-C.T, M.-Y.C and Y.-J.S; Writing-Review \& Editing, P.-Y.Y, T.-Y.H and B.-M.H; Visualization, B.-M.H; Supervision, B.-M.H, P-Y.Y, H.-C.T and J.-S.C; Project Administration, B.-M.H and H.-C.T; Funding Acquisition, B.-M.H, M.-Y.C, P-Y.Y and H.-C.T.

Funding: This research was funded by the Ministry of Science and Technology of Taiwan (MOST 106-2116-M-194-013), the Centers for Disease Control, Taiwan, R.O.C. (MOHW105-CDC-C-114-112601 and 106-CDC-C-114-122601), the Buddhist Tzu Chi Hospital, R.O.C., Show Chwan Health Care System and Cheng Hsin General Hospital (TCRD106-37, RD107023, CHGH106-01). This research was also supported by the Center for Innovative Research on Aging Society (CIRAS) from The Featured Areas Research Center Program within the framework of the Higher Education Sprout Project by the Ministry of Education (MOE) in Taiwan.

Conflicts of Interest: The authors declare that they have no conflict of interest.

\section{References}

1. Alaei, N.; Aziemzadeh, M.; Bahador, A. Antimicrobial resistance profiles and genetic elements involved in carbapenem resistance in acinetobacter baumannii isolates from a referral hospital in Southern Iran. J. Glob. Antimicrob. Resist. 2016, 5, 75-79. [CrossRef] [PubMed]

2. Maleki, A.; Vandyousefi, J.; Mirzaie, Z.; Ghafourian, S.; Kazemian, H.; Sadeghifard, N. Molecular analysis of the isolates of acinetobacter baumannii isolated from tehran hospitals using ERIC-PCR method. Mod. Med. Lab. J. 2016, 1, 12-16. [CrossRef]

3. Rosa, R.; Depascale, D.; Cleary, T.; Fajardo-Aquino, Y.; Kett, D.H.; Munoz-Price, L.S. Differential environmental contamination with acinetobacter baumannii based on the anatomic source of colonization. Am. J. Infect. Control. 2014, 42, 755-757. [CrossRef] [PubMed]

4. Zhang, H.-Z.; Zhang, J.-S.; Qiao, L. The acinetobacter baumannii group: A systemic review. World J. Emerg. Med. 2013, 4, 169. [CrossRef] [PubMed]

5. Taitt, C.R.; Leski, T.; Stockelman, M.G.; Craft, D.W.; Zurawski, D.V.; Kirkup, B.C.; Vora, G.J. Antimicrobial resistance determinants in acinetobacter baumannii isolates taken from military treatment facilities. Antimicrob. Agents Chemother. 2014, 58, 767-781. [CrossRef] [PubMed]

6. Peleg, A.Y.; Seifert, H.; Paterson, D.L. Acinetobacter baumannii: Emergence of a successful pathogen. Clin. Microbiol. Rev. 2008, 21, 538-582. [CrossRef] [PubMed]

7. Jawad, A.; Snelling, A.; Heritage, J.; Hawkey, P. Exceptional desiccation tolerance of acinetobacter radioresistens. J. Hosp. Infect. 1998, 39, 235-240. [CrossRef]

8. Fournier, P.E.; Richet, H.; Weinstein, R.A. The epidemiology and control of acinetobacter baumannii in health care facilities. Clin. Infect. Dis. 2006, 42, 692-699. [CrossRef] [PubMed]

9. Denton, M.; Wilcox, M.; Parnell, P.; Green, D.; Keer, V.; Hawkey, P.; Evans, I.; Murphy, P. Role of environmental cleaning in controlling an outbreak of acinetobacter baumannii on a neurosurgical intensive care unit. J. Hosp. Infect. 2004, 56, 106-110. [CrossRef] [PubMed] 
10. Garnacho-Montero, J.; Ortiz-Leyba, C.; Jimenez-Jimenez, F.; Barrero-Almodovar, A.; Garcia-Garmendia, J.; Bernabeu-Wittell, M.; Gallego-Lara, S.; Madrazo-Osuna, J. Treatment of multidrug-resistant acinetobacter baumannii ventilator-associated pneumonia (VAP) with intravenous colistin: A comparison with imipenem-susceptible vap. Clin. Infect. Dis. 2003, 36, 1111-1118. [CrossRef] [PubMed]

11. Bartual, S.G.; Seifert, H.; Hippler, C.; Luzon, M.A.D.; Wisplinghoff, H.; Rodríguez-Valera, F. Development of a multilocus sequence typing scheme for characterization of clinical isolates of acinetobacter baumannii. J. Clin. Microbiol. 2005, 43, 4382-4390. [CrossRef] [PubMed]

12. Bou, G.; Cervero, G.; Dominguez, M.; Quereda, C.; Martinez-Beltran, J. PCR-based DNA fingerprinting (REP-PCR, AP-PCR) and pulsed-field GEL electrophoresis characterization of a nosocomial outbreak caused by imipenem-and meropenem-resistant acinetobacter baumannii. Clin. Microbiol. Infect. 2000, 6, 635-643. [CrossRef] [PubMed]

13. Seifert, H.; Gerner-Smidt, P. Comparison of ribotyping and pulsed-field gel electrophoresis for molecular typing of acinetobacter isolates. J. Clin. Microbiol. 1995, 33, 1402-1407. [PubMed]

14. Vila, J.; Marcos, M.; De Anta, M.J. A comparative study of different pcr-based DNA fingerprinting techniques for typing of the acinetobacter calcoaceticus-A. Baumannii complex. J. Med. Microbiol. 1996, 44, 482-489. [CrossRef] [PubMed]

15. Karlowsky, J.A.; Draghi, D.C.; Jones, M.E.; Thornsberry, C.; Friedland, I.R.; Sahm, D.F. Surveillance for antimicrobial susceptibility among clinical isolates of pseudomonas aeruginosa and acinetobacter baumannii from hospitalized patients in the United States, 1998 to 2001. Antimicrob. Agents Chemother. 2003, 47, 1681-1688. [CrossRef] [PubMed]

16. Fournier, P.-E.; Vallenet, D.; Barbe, V.; Audic, S.; Ogata, H.; Poirel, L.; Richet, H.; Robert, C.; Mangenot, S.; Abergel, C. Comparative genomics of multidrug resistance in acinetobacter baumannii. PLoS Genet. 2006, 2, e7. [CrossRef] [PubMed]

17. Falagas, M.; Kopterides, P. Risk factors for the isolation of multi-drug-resistant acinetobacter baumannii and pseudomonas aeruginosa: A systematic review of the literature. J. Hosp. Infect. 2006, 64, 7-15. [CrossRef] [PubMed]

18. Hsueh, P.-R.; Teng, L.-J.; Chen, C.-Y.; Chen, W.-H.; Ho, S.-W.; Luh, K.-T. Pandrug-resistant acinetobacter baumannii causing nosocomial infections in a university hospital, Taiwan. Emerg. Infect. Dis. 2002, 8, 827. [CrossRef] [PubMed]

19. Dijkshoorn, L.; Nemec, A.; Seifert, H. An increasing threat in hospitals: Multidrug-resistant acinetobacter baumannii. Nat. Rev. Microbiol. 2007, 5, 939-951. [CrossRef] [PubMed]

20. Visca, P.; Seifert, H.; Towner, K.J. Acinetobacter infection-An emerging threat to human health. IUBMB Life 2011, 63, 1048-1054. [CrossRef] [PubMed]

21. Karumathil, D.P.; Yin, H.-B.; Kollanoor-Johny, A.; Venkitanarayanan, K. Effect of chlorine exposure on the survival and antibiotic gene expression of multidrug resistant acinetobacter baumannii in water. Int. J. Environ. Res. Public Health 2014, 11, 1844-1854. [CrossRef] [PubMed]

22. Francey, T.; Gaschen, F.; Nicolet, J.; Burnens, A.P. The role of acinetobacter baumannii as a nosocomial pathogen for dogs and cats in an intensive care unit. J. Vet. Intern. Med. 2000, 14, 177-183. [CrossRef] [PubMed]

23. Vaneechoutte, M.; Devriese, L.A.; Dijkshoorn, L.; Lamote, B.; Deprez, P.; Verschraegen, G.; Haesebrouck, F. Acinetobacter baumannii-infected vascular catheters collected from horses in an equine clinic. J. Clin. Microbiol. 2000, 38, 4280-4281. [PubMed]

24. Landers, T.F.; Cohen, B.; Wittum, T.E.; Larson, E.L. A review of antibiotic use in food animals: Perspective, policy, and potential. Public Health Rep. 2012, 127, 4-22. [CrossRef] [PubMed]

25. McEwen, S.A.; Fedorka-Cray, P.J. Antimicrobial use and resistance in animals. Clin. Infect. Dis. 2002, 34, S93-S106. [CrossRef] [PubMed]

26. Widyasari-Mehta, A.; Hartung, S.; Kreuzig, R. From the application of antibiotics to antibiotic residues in liquid manures and digestates: A screening study in one european center of conventional pig husbandry. J. Environ. Manag. 2016, 177, 129-137. [CrossRef] [PubMed]

27. Kemper, N. Veterinary antibiotics in the aquatic and terrestrial environment. Ecol. Indic. 2008, 8, 1-13. [CrossRef] 
28. Boerlin, P.; Travis, R.; Gyles, C.L.; Reid-Smith, R.; Janecko, N.; Lim, H.; Nicholson, V.; McEwen, S.A.; Friendship, R.; Archambault, M. Antimicrobial resistance and virulence genes of escherichia coli isolates from swine in ontario. Appl. Environ. Microbiol. 2005, 71, 6753-6761. [CrossRef] [PubMed]

29. Phuong Hoa, P.T.; Nonaka, L.; Hung Viet, P.; Suzuki, S. Detection of the SUL1, SUL2, and SUL3 genes in sulfonamide-resistant bacteria from wastewater and shrimp ponds of north vietnam. Sci. Total Environ. 2008, 405, 377-384. [CrossRef] [PubMed]

30. Sarmah, A.K.; Meyer, M.T.; Boxall, A.B. A global perspective on the use, sales, exposure pathways, occurrence, fate and effects of veterinary antibiotics (VAS) in the environment. Chemosphere 2006, 65, 725-759. [CrossRef] [PubMed]

31. Cai, Y.; Cai, Y.e.; Cheng, J.; Mou, S.; Yiqiang, L. Comparative study on the analytical performance of three waveforms for the determination of several aminoglycoside antibiotics with high performance liquid chromatography using amperometric detection. J. Chromatogr. A 2005, 1085, 124-130. [CrossRef] [PubMed]

32. Butaye, P.; Devriese, L.A.; Haesebrouck, F. Antimicrobial growth promoters used in animal feed: Effects of less well known antibiotics on gram-positive bacteria. Clin. Microbiol. Rev. 2003, 16, 175-188. [CrossRef] [PubMed]

33. Moradi, J.; Hashemi, F.B.; Bahador, A. Antibiotic resistance of acinetobacter baumannii in Iran: A systemic review of the published literature. Osong Public Health Res. Perspect. 2015, 6, 79-86. [CrossRef] [PubMed]

34. Tsai, H.C.; Chou, M.Y.; Wu, C.C.; Wan, M.T.; Kuo, Y.J.; Chen, J.S.; Huang, T.Y.; Hsu, B.M. Seasonal distribution and genotyping of antibiotic resistant strains of listeria innocua isolated from a river basin categorized by ERIC-PCR. Int. J. Environ. Res. Public Health 2018, 15, 1559. [CrossRef] [PubMed]

35. Chen, T.L.; Siu, L.K.; Wu, R.C.; Shaio, M.F.; Huang, L.Y.; Fung, C.P.; Lee, C.M.; Cho, W.L. Comparison of one-tube multiplex PCR, automated ribotyping and intergenic spacer (ITS) sequencing for rapid identification of acinetobacter baumannii. Clin. Microbiol. Infect. 2007, 13, 801-806. [CrossRef] [PubMed]

36. Soni, D.K.; Singh, M.; Singh, D.V.; Dubey, S.K. Virulence and genotypic characterization of listeria monocytogenes isolated from vegetable and soil samples. BMC Microbiol. 2014, 14, 241. [CrossRef] [PubMed]

37. Clinical and Laboratory Standards Institute. Methods for Dilution Antimicrobial Susceptibility Tests for Bacteria That Grow Aerobically, Approved Standard M7-A7, 7th ed.; Clinical and Laboratory Standards Institute: Wayne, PA, USA, 2006.

38. Fernando, D.M.; Khan, I.U.; Patidar, R.; Lapen, D.R.; Talbot, G.; Topp, E.; Kumar, A. Isolation and characterization of acinetobacter baumannii recovered from campylobacter selective medium. Front. Microbiol. 2016, 7, 1871. [CrossRef] [PubMed]

39. McDonald, L.C.; Banerjee, S.N.; Jarvis, W.R.; System, N.N.I.S. Seasonal variation of acinetobacter infections: 1987-1996. Clin. Infect. Dis. 1999, 29, 1133-1137. [CrossRef] [PubMed]

40. Chu, Y.W.; Leung, C.M.; Houang, E.T.S.; Ng, K.C.; Leung, C.B.; Leung, H.Y.; Cheng, A.F.B. Skin carriage of acinetobacters in Hong Kong. J. Clin. Microbiol. 1999, 37, 2962-2967. [PubMed]

41. Girlich, D.; Poirel, L.; Nordmann, P. First isolation of the BLAOXA-23 carbapenemase gene from an environmental acinetobacter baumannii isolate. Antimicrob. Agents Chemother. 2010, 54, 578-579. [CrossRef] [PubMed]

42. Turano, H.; Gomes, F.; Medeiros, M.; Oliveira, S.; Fontes, L.C.; Sato, M.I.; Lincopan, N. Presence of high-risk clones of OXA-23-producing acinetobacter baumannii (ST79) and SPM-1-producing pseudomonas aeruginosa (ST277) in environmental water samples in Brazil. Diagn. Microbiol. Infect. Dis. 2016, 86, 80-82. [CrossRef] [PubMed]

43. Gestal, M.C.; Zurita, J.; Gualpa, G.; Gonzalez, C.; Mino, A.P. Early detection and control of an acinetobacter baumannii multi-resistant outbreak in a hospital in quito, Ecuador. J. Infect. Dev. Ctries. 2016, 10, 1294-1298. [CrossRef] [PubMed]

44. Aygün, G.; Demirkiran, O.; Utku, T.; Mete, B.; Ürkmez, S.; Yılmaz, M.; Yaşar, H.; Dikmen, Y.; Öztürk, R. Environmental contamination during a carbapenem-resistant acinetobacter baumannii outbreak in an intensive care unit. J. Hosp. Infect. 2002, 52, 259-262. [CrossRef] [PubMed]

45. Umezawa, K.; Asai, S.; Ohshima, T.; Iwashita, H.; Ohashi, M.; Sasaki, M.; Kaneko, A.; Inokuchi, S.; Miyachi, H. Outbreak of drug-resistant acinetobacter baumannii ST219 caused by oral care using tap water from contaminated hand hygiene sinks as a reservoir. Am. J. Infect. Control. 2015, 43, 1249-1251. [CrossRef] [PubMed] 
46. Ferreira, A.E.; Marchetti, D.P.; De Oliveira, L.M.; Gusatti, C.D.S.; Fuentefria, D.B.; Corcao, G. Presence of OXA-23-producing isolates of acinetobacter baumannii in wastewater from hospitals in Southern Brazil. Microbiol. Drug Resist. 2011, 17, 221-227. [CrossRef] [PubMed]

47. Ece, G.; Erac, B.; Cetin, H.Y.; Ece, C.; Baysak, A. Antimicrobial susceptibility and clonal relation between acinetobacter baumannii strains at a tertiary care center in Turkey. Jundishapur J. Microbiol. 2015, 8, e15612. [CrossRef] [PubMed]

48. Aljindan, R.; Alsamman, K.; Elhadi, N. ERIC-PCR genotyping of acinetobacter baumannii isolated from different clinical specimens. Saudi J. Med. Med. Sci. 2018, 6, 13.

49. Heidari, H.; Halaji, M.; Taji, A.; Kazemian, H.; Shamsabadi, M.S.; Sisakht, M.T.; Ebrahim-Saraie, H.S. Molecular analysis of drug-resistant acinetobacter baumannii isolates by ERIC-PCR. Meta Gene 2018, 17, 132-135. [CrossRef]

(C) 2018 by the authors. Licensee MDPI, Basel, Switzerland. This article is an open access article distributed under the terms and conditions of the Creative Commons Attribution (CC BY) license (http://creativecommons.org/licenses/by/4.0/). 